\title{
As leis de gestão democrática da Educação nos estados brasileiros
}

\section{The democratic education administration laws in Brazilian states}

\author{
Ângelo Ricardo de Souza* \\ Pierre André Garcia Pires ${ }^{* *}$
}

\begin{abstract}
RESUMO
Este artigo analisa o panorama nacional referente à normatização da gestão democrática da educação, em diálogo com o artigo 14 da Lei de Diretrizes e Bases da Educação Nacional (Lei n $\left.{ }^{\circ} 9.394 / 1996\right)$ e com o artigo $9^{\circ}$ da Lei do Plano Nacional de Educação 2014-2024 (Lei nº 13.005/2014). O texto promoveu um levantamento nas páginas da internet das Assembleias Legislativas dos Estados e na Câmara Distrital, buscando por peças legais que tratem da matéria. A leitura dos documentos demonstrou um quadro que evidencia que apenas 11 estados da federação e o Distrito Federal possuem leis próprias de gestão democrática. Há ainda um universo de outras leis que versam sobre aspectos da gestão democrática, como regras sobre as formas de provimento de diretores escolares, conselhos de escola, dentre outros tópicos. Mais importante, todavia, é a análise do material que demonstrou uma focalização da legislação na gestão da escola, sendo que pouquíssimas leis estaduais tratam da gestão democrática do sistema de ensino.
\end{abstract}

Palavras-chave: Gestão democrática. Políticas educacionais. Legislação educacional.

\footnotetext{
ABSTRACT

This article analyzes the Brazilian national panorama regarding the legalization of the democratic administration of education, in dialogue with article 14 of the Lei de Diretrizes e Bases da Educação Nacional

* Universidade Federal do Paraná. Setor de Educação. Curitiba, Paraná, Brasil. E-mail: angelo@ufpr.br. https://orcid.org/0000-0002-0246-3207

** Universidade Federal do Acre. Rio Branco, Acre, Brasil. E-mail: pierreufac@gmail.com. https://orcid.org/0000-0002-2408-876X
} 
(National Law of Education) (n. 9394/1996), and with article 9 of the Lei do Plano Nacional de Educação 2014-2024 (The National Education Plan Law) (n. 13005/2014). The text promoted a survey in the Legislative Houses websites, looking for legal pieces that deal with the matter. The analysis of the documents showed that only eleven states of the federation and the Federal District have their own laws of democratic administration. There is also a universe of other laws that deal with aspects of democratic administration, such as rules about school principals, school boards, among other topics. More important, however is the fact that the analysis of the material demonstrated a focus of legislation on administration of school units, with very few state laws dealing with the democratic administration of the school system.

Keywords: Democratic Administration; Education Policies; Education Laws.

\section{Introdução}

Não parece possível a democracia sem as condições reais de sua efetivação. Isto é, a conversão da democracia como princípio pressupõe a participação como elemento primeiro. Diversos autores (CAMARGO, 1997; BOBBIO, 2000; LIMA, 2001; SOUZA, 2007b, 2009a; entre outros) já discutiram a participação como condição primeira, mas, ao mesmo tempo, tipificaram-na de distintas formas, uma vez que a despeito de se tratar de uma expressão omnipresente nos discursos políticos, há razões e procedimentos que ora a incentivam, ora a dificultam e, ainda, por vezes a inviabilizam.

Tão mais democrático será um processo quanto mais participação crítica obtivermos. Essa criticidade se associa à ideia de autonomia. Autonomia é algo que sempre ocorre em relação, ou seja, ela nunca ocorre de maneira isolada. Assim, não faz sentido se pensar a autonomia como a independência para se fazer o que se quer:

Reclamamos de nossa dependência, da subordinação de nossas ações a desígnios determinados externamente, da heteronomia. O que temos, entretanto, no coletivo da polis, é uma situação de interdependência. [Logo] a autonomia não significa solidão (RIOS, 1995, p. 16).

A autonomia da escola e da educação, a autonomia construída, é uma autonomia relativa e relacional, pois sempre acontece em relação, visto que a 
escola e o sistema educacional autônomos não são aqueles com "possibilidade de agir independentemente daqueles que estão à [sua] volta [...], significa justamente agir levando-os em consideração" (RIOS, 1995, p. 17). Ou ainda, a

autonomia [...] conduz diretamente ao problema político e social. [...] não podemos desejar a autonomia sem desejá-la para todos e que sua realização só pode conceber-se plenamente como empreitada coletiva. [...] a autonomia só é concebível como um problema e uma relação social (CASTORIADIS, 1995, p. 129-130).

A descentralização, em tese, incentiva a autonomia e o faz (ou deveria fazer) num plano prioritariamente político, pois permite (ou permitiria) aos sujeitos da escola e da educação as possibilidades de definirem em conjunto (nas suas relações) os rumos da própria instituição e do sistema educacional.

Sendo o objetivo da política criar as instituições que, interiorizadas pelos indivíduos, facilitem ao máximo seu acesso à autonomia individual e à possibilidade de participação efetiva em todo poder explícito existente na sociedade e em suas instituições (CASTORIADIS, 1995, p. 69), certamente as resultantes políticas da descentralização deveriam levar à autonomia dos sujeitos e das próprias instituições. Esta é a veia democrática da autonomia e da descentralização.

Bem, se temos participação com autonomia e com a realização e efetivação do poder de maneira mais próxima às pessoas, então, são essas pessoas as responsáveis pela edificação das regras que dimensionam o fazer coletivo. $\mathrm{Ou}$ seja, a democracia só se efetiva como um projeto coletivo, construído coletivamente. Logo, propostas de gestão democrática (GD) não podem nascer em gabinetes de gestores, pois, ou elas contam com a mais ampla participação dos interessados (sujeitos da escola e da educação), ou ela é natimorta.

Se o poeta nos disse, porém, que "As leis não bastam. Os lírios não nascem da lei", ele também afirmou que "Meu nome é tumulto, e escreve-se na pedra" (DRUMMOND DE ANDRADE, [1945] 2012)1. Assim, as leis não bastam, mas é preciso encontrar mecanismos que garantam o "tumulto": o direito ao contraditório, à expressão e ao livre pensamento, à apresentação das diferentes ideias e propostas sobre, nesse caso, os rumos da educação e da escola. Logo, a regulamentação da GD não garantirá a mais ampla democracia apenas pela

1 Esse extrato faz parte do poema "Nosso Tempo", que também pode ser encontrado em https://www.letras.mus.br/carlos-drummond-de-andrade/881736/. 
sua existência, mas sem ela teremos dificuldades em fazer valer um conceito como este:

A gestão democrática é aqui compreendida então como um processo político no qual as pessoas que atuam na/sobre a escola/educação identificam problemas, discutem, deliberam e planejam, encaminham, acompanham, controlam e avaliam o conjunto das ações voltadas ao desenvolvimento da própria escola/sistema na busca da solução daqueles problemas. Esse processo, sustentado no diálogo, na alteridade e no reconhecimento às especificidades técnicas das diversas funções presentes na escola/sistema, tem como base a participação efetiva de todos os segmentos da comunidade escolar/sociedade, o respeito às normas coletivamente construídas para os processos de tomada de decisões e a garantia de amplo acesso às informações aos sujeitos (SOUZA, 2009a, p. 125-126).

Na dimensão legal, melhor discutida adiante, a Lei Federal n 13.005/2014, que institui o Plano Nacional de Educação (PNE), dispõe sobre a gestão democrática como uma de suas diretrizes, reforçando o princípio constitucional disposto no art. 206 da Carta Magna, que apresenta a GD como um dos princípios a organizar a educação pública brasileira.

Esses dispositivos dialogam com a Lei Federal no 9.394/1996 (Lei de Diretrizes e Bases da Educação Nacional - LDB) e com uma demanda histórica de educadores e da sociedade, em favor da democratização da gestão escolar, que é derivada do reconhecimento da necessidade de se constituir no universo escolar e educacional condições mais horizontais, de maior diálogo e participação, favorecendo a socialização do poder institucional e a constituição de um ambiente mais adequado ao ensino e à aprendizagem.

O PNE ainda dispõe, no artigo $9^{\circ}$, acerca da necessidade de os estados, o Distrito Federal e os municípios aprovarem regras específicas para a gestão democrática em seus sistemas de ensino, para tanto, estabelece um prazo.

Este trabalho, justamente, apresenta uma leitura atualizada da condição de normatização do artigo $9^{\circ}$, do PNE, buscando mostrar, por meio de um panorama dos estados da federação, em que condição se encontram os processos de normatização da GD e o cumprimento dos dispositivos legais mencionados. Ademais, analisa o alcance e a (in)suficiência dessa legislação, tanto das exigências formais quanto das necessidades de democratização da gestão da educação pública. 


\section{O princípio da gestão democrática na legislação}

A Constituição Federal (CF) de 1988, em seu artigo 206, apresenta o conjunto de princípios que solidificam a educação nacional. Dentre esses, o inciso VI indica a "gestão democrática do ensino público, na forma da lei".

A lei mencionada na CF deveria ser a Lei de Diretrizes e Bases da Educação Nacional (LDB), Lei no 9.394/1996. Essa peça legal ratifica, em seu artigo $3^{\circ}$, que também trata dos princípios da educação nacional, aquilo que a CF já indicava, mas dispõe de maneira um pouco mais específica no inciso VIII: "gestão democrática do ensino público, na forma desta Lei e da legislação dos sistemas de ensino". Isto é, a LDB adianta que tratará da matéria, mas que os sistemas estaduais e municipais de ensino poderão/deverão regulamentá-la também nas suas próprias esferas.

Mais adiante, no artigo 14, a LDB retoma o tema e indica:

Art. 14: Os sistemas de ensino definirão as normas da gestão democrática do ensino público na educação básica, de acordo com as suas peculiaridades e conforme os seguintes princípios:

I - participação dos profissionais da educação na elaboração do projeto pedagógico da escola;

II - participação das comunidades escolar e local em conselhos escolares ou equivalentes. (BRASIL, 1996).

Ou seja, a LDB informa que GD é objeto de regulamentação nas normas de cada sistema de ensino, desde que estejam garantidos os dois tópicos indicados nos incisos I e II, os quais tomam como referência a noção de participação como elemento emblemático da democracia, sem, porém, detalhá-la para além do exposto nos itens.

Tal participação é compreendida em duas frentes, uma interna à escola, com a ação dos trabalhadores da educação na elaboração do projeto da escola e, de outro lado, externa, com a inclusão de pessoas da comunidade na qual a escola está inserida na composição e funcionamento dos conselhos escolares.

Nada mais é tratado sobre a GD da educação básica nessa lei. E isto implicou, durante os últimos 20 anos, na composição das formas legais mais distintas e o quadro mais diferenciado sobre a matéria no Brasil, como veremos mais adiante. 
De toda maneira, a forma como tanto a CF quanto a LDB tratam o princípio suscita dúvidas sobre o alcance da gestão democrática. A questão é que a expressão usada em ambas as legislações é "gestão democrática do ensino público". Isto pode indicar que o constituinte/legislador pretendia que tal princípio alcançasse somente a gestão da escola (local onde o ensino se efetiva), mas não a organização e gestão do sistema educativo como um todo. Não há, salvo melhor juízo, posicionamento legal sobre essa questão, mas, como mostra o panorama exposto no próximo item, as unidades da federação (UF) parecem ter essa compreensão, uma vez que pouquíssimas fazem menção em sua legislação à democratização da gestão do sistema educacional. Curiosamente o mesmo ocorre em outras frentes, como é o caso dos sindicatos docentes, os quais, quando tratam da matéria, também a reduzem ao universo escolar, sem demandar, na maior parte dos casos, um alcance da GD ao sistema educacional (SOUZA; BRUEL, 2016).

Em 2014, após três anos de tramitação, aprovou-se o novo Plano Nacional de Educação por meio da Lei Federal ${ }^{\circ}$ 13.005/2014. Aqui temos uma dedicação um pouco maior à matéria em relação à $\mathrm{LDB}$. $\mathrm{O}$ PNE destinou uma meta para o assunto, a de número 19. No entanto, mesmo antes, já abordou a matéria nos $\operatorname{artigos} 2^{\circ}, 6^{\circ}$ e $9^{\circ}$ :

Art. $2^{\circ}$ São diretrizes do PNE:

VI - promoção do princípio da gestão democrática da educação pública; $[\ldots]$

Art. $6^{\circ}$ A União promoverá a realização de pelo menos 2 (duas) conferências nacionais de educação até o final do decênio, precedidas de conferências distrital, municipais e estaduais, articuladas e coordenadas pelo Fórum Nacional de Educação, instituído nesta Lei, no âmbito do Ministério da Educação.

$[\ldots]$

Art. $9^{\circ}$ Os Estados, o Distrito Federal e os Municípios deverão aprovar leis específicas para os seus sistemas de ensino, disciplinando a gestão democrática da educação pública nos respectivos âmbitos de atuação, no prazo de 2 (dois) anos contado da publicação desta Lei, adequando, quando for o caso, a legislação local já adotada com essa finalidade. (BRASIL, 2014).

No primeiro, o plano em consonância com a CF e com a LDB relembra a GD como princípio na definição das diretrizes do próprio plano e da educação brasileira. No artigo $6^{\circ}$, ainda que não utilize a expressão "gestão democrática", o texto indica a necessidade de constituição de mecanismo democrático e democratizante para a definição das diretrizes da macropolítica educacional. 
E, no artigo $9^{\circ}$, o texto determina que estados, Distrito Federal e os municípios brasileiros devem, em prazo até junho de 2016 (já expirado, portanto), elaborar sua legislação própria acerca da matéria. Como veremos, apenas 11 estados, além do Distrito Federal (DF), a têm até o final do ano de 2017. É provável que a proporção de municípios que a tenham seja ainda menor, considerando que são entes que, de um lado, tendem a ter menor capacidade técnica para o assunto e, de outro, são menos tensionados nas disputas das políticas (educacionais) que os governos estaduais, dada a menor pressão e controle social em tal esfera de governo (ARRETCHE, 2004).

Entretanto, o plano ainda trata da matéria em duas outras partes: na meta 7, indicando duas estratégias, e na meta 19, já mencionada. Naquela atesta:

7.4) induzir processo contínuo de autoavaliação das escolas de educação básica, por meio da constituição de instrumentos de avaliação que orientem as dimensões a serem fortalecidas, destacando-se a elaboração de planejamento estratégico, a melhoria contínua da qualidade educacional, a formação continuada dos (as) profissionais da educação e o aprimoramento da gestão democrática;

$[\ldots]$

7.16) apoiar técnica e financeiramente a gestão escolar mediante transferência direta de recursos financeiros à escola, garantindo a participação da comunidade escolar no planejamento e na aplicação dos recursos, visando à ampliação da transparência e ao efetivo desenvolvimento da gestão democrática. (BRASIL, 2014).

Essas estratégias estão dispostas na meta 7, que versa sobre a qualidade da educação. Assim, a ideia parece ser a de articulação da democracia como condição ou critério de qualidade, o que é algo interessante. Os textos não são exatamente inovadores, mas apontam ideias aparentemente adequadas aos propósitos de democratização da educação pública e de compreensão desse avanço como uma condição de qualidade educacional.

Finalmente, a meta 19, na qual o caput do texto afirma:

Meta 19: assegurar condições, no prazo de 2 (dois) anos, para a efetivação da gestão democrática da educação, associada a critérios técnicos de mérito e desempenho e à consulta pública à comunidade escolar, no âmbito das escolas públicas, prevendo recursos e apoio técnico da União para tanto. (BRASIL, 2014). 
Trata-se de um dos textos que menos tem compreensão e aplicação direta em todo o plano, pois sugere a ideia de que o país tem um prazo de dois anos (findado em junho de 2016) para a efetivação da gestão democrática, mas indica que compreende a ideia de GD como a definição de critérios que associem mérito e participação na gestão escolar pública.

Por este caminho, o legislador parecia resumir a GD à forma de provimento de diretores escolares como indica a estratégia 19.1, o que, por certo, é um aspecto importante da GD, mas absolutamente insuficiente para o cumprimento do princípio constitucional, já mencionado.

Para dar conta dessa meta, o texto elenca oito estratégias, voltadas a uma série de aspectos edificadores ou complementares à meta. Em sua maioria, há uma tendência de diálogo forte entre o objetivo da estratégia e as orientações da legislação e que a literatura do campo faz para a temática. A exceção é a estratégia $19.8^{2}$, que mesmo se articulando com a meta, não dá evidências de contribuir com o desenvolvimento da gestão democrática da educação pública no país.

De outro lado, com as estratégias 19.2, 19.3 e 19.5, o texto compreende elementos para além da gestão escolar, pois inclui ferramentas de gestão democrática dos sistemas de ensino. A ênfase, todavia, continua recaindo sobre a escola, lamentavelmente. Isto é, não é inadequado se compreender que a escola é o epicentro do sistema educacional e, por isso, é preciso que a sua gestão se paute pelos princípios e procedimentos democráticos. Contudo, não é suficiente, uma vez que é bastante razoável supor que diretores tenderão a agir - em relação aos trabalhadores da escola e aos alunos e seus familiares - de forma parecida como são tratados pelos gestores dos sistemas. Ou seja, se queremos relações mais horizontais no cotidiano escolar, um bom incentivo a isto, é justamente horizontalizar as relações no âmbito do próprio sistema educacional. Assim, buscar formas de se democratizar a gestão do sistema educacional como um todo se mostra urgente.

\section{Entes federados e as formas de legislar sobre a gestão democrática}

A partir da década de 1980, os estados, os municípios e o Distrito Federal, de forma a organizarem os seus sistemas de ensino, elaboram leis específicas

2 “19.8) desenvolver programas de formação de diretores e gestores escolares, bem como aplicar prova nacional específica, a fim de subsidiar a definição de critérios objetivos para o provimento dos cargos, cujos resultados possam ser utilizados por adesão.” (BRASIL, 2014). 
ou criam normas, decretos ou manuais que dispõem sobre a gestão democrática em seus sistemas. Isso se evidenciou de maneira mais emblemática a partir da LDB, uma vez que ela autoriza os entes federados a organizarem seu próprio regramento acerca da matéria, como discutido. Assim, de formas distintas, os legislativos estaduais e municipais vêm tratando do assunto, seja regulamentando a gestão democrática, seja lidando com aspectos concernentes a ela.

A inovação que representou a inclusão do princípio da gestão democrática na Constituição Federal reforçou/consolidou ações muitas vezes já realizadas nos sistemas de ensino e amparadas por leis criadas pelas Secretarias Estaduais de Educação ou pelos legislativos estaduais.

Nosso levantamento realizado sobre o panorama dos estados descreve como este princípio é cumprido em cada contexto estadual da federação. Metodologicamente, produzimos uma busca em sites das Secretarias Estaduais de Educação e Casas Legislativas (Assembleias Estaduais e Câmara Distrital), ou em sites de busca geral indicando a legislação pertinente, ou ainda obtivemos respostas a encaminhamentos feitos por e-mail pelos autores aos órgãos estaduais de gestão educacional. Há constante alteração dessas informações, considerando os movimentos próprios da política educacional e das pressões sociais e respostas do Estado (SOUZA, 2014), por isso, esta atualização é sempre importante. Outros estudos já produziram esforços importantes nessa direção (BRASIL, 2014; PIRES, 2016).

Os dados do levantamento revelam que os principais mecanismos de gestão democrática, considerados na legislação, estão relacionados à eleição de diretores ou a criação/funcionamento de conselhos escolares, pois encontramos pelo menos 21 peças legais, em 15 estados distintos, que se referem a um dos dois elementos. Alguns desses, ainda, têm uma legislação mais abrangente, tratando de outros aspectos ou do próprio princípio constitucional em questão. Contudo, do conjunto de 27 unidades federativas, como citado anteriormente, identificamos apenas 11 estados e o Distrito Federal, os quais possuem normativa própria, regulamentando o artigo 206 da CF e o artigo 14 da LDB.

Como vimos, o texto da Lei do PNE estabelece um prazo que já expirou para que todos os entes federados regulamentem a gestão democrática em sua circunscrição. Isto quer dizer que apenas $44,4 \%$ das UF o fizeram.

Os 11 estados mencionados são Acre, Amapá e Rondônia, na região Norte; Piauí, Rio Grande do Norte, Alagoas e Sergipe, no Nordeste; Rio de Janeiro no Sudeste; Rio Grande do Sul na região Sul e; Mato Grosso e Goiás, além do Distrito Federal, na região Centro-Oeste.

As peças legais dessas UF apresentam, em sua maioria, tópicos que incorporam elementos da teoria democrática e da literatura da gestão democrática no país, por isso, inclusive apontam mecanismos que possibilitam a GD no contexto 
escolar, como eleição de diretores e/ou vice-diretores, criação e funcionamento de conselhos escolares, conselhos de classe, conselhos deliberativos, grêmios estudantis e associações de pais e mestres.

Entretanto, apenas em dois contextos (RS e DF) encontramos preocupações com a gestão democrática do próprio sistema de ensino, uma vez que nos outros 9 estados, temos apenas um esforço de estabelecer padrões de gestão para as unidades escolares, sem menção à organização do sistema como um todo.

No estado do Rio Grande do Sul, encontramos a Lei ${ }^{\circ} 10.576$, de 14 de novembro de 1995, que parece ser a mais antiga peça legal sobre a GD no país, porque é inclusive anterior à LDB. Essa lei foi atualizada pela Lei no 13.999 , de 15 de maio de 2012. Tais leis amparam a instituição escolar no que se refere à autonomia e à transparência na gestão administrativa, financeira e pedagógica; a livre organização e a participação dos segmentos da comunidade escolar nos processos decisórios; a descentralização das unidades escolares reforça a valorização dos profissionais da educação e a eficiência no uso de recursos. Além disso, tratam do Regime de Colaboração, que também deve se pautar pela GD, e organizam a ação do estado e seus municípios no atendimento à educação básica.

No Distrito Federal, a normatização do princípio se dá por meio da Lei $\mathrm{n}^{\mathrm{o}} 4.751$, de fevereiro de 2012, que dispõe sobre o sistema de ensino e a gestão democrática do sistema de ensino público, portanto, aliando a GD como elemento central (princípio) da organização do sistema educativo. Para tanto, a norma indica a importância da participação da comunidade escolar na criação de órgãos colegiados, como o conselho escolar, o conselho de classe, o grêmio estudantil e a eleição de diretor e vice-diretor.

A finalidade da lei é garantir a centralidade da escola no sistema e seu caráter público quanto ao financiamento, à gestão e à destinação de recursos. Entre suas características, destacam-se a autonomia e a transparência da gestão e das unidades escolares em todos os seus níveis, nos aspectos pedagógicos, administrativos e financeiros e a elaboração do projeto político-pedagógico.

Dentre os demais 9 estados, temos o Acre, que tem longa tradição com a questão, pois desde 1996, o estado tem legislação sobre a GD. Atualmente, essa UF tem a Lei $\mathrm{n}^{\mathrm{o}} 3.141$, de 22 de julho de 2016, que configura a gestão democrática com um modelo de provimento de diretores escolares e demais integrantes da equipe diretiva e a composição e efetivação do conselho escolar.

Entre alguns princípios da lei encontramos a garantia de centralidade da escola no sistema; gestão participativa e descentralizadora, no que se refere à autonomia para os sistemas de ensino elaborarem e implementarem seus projetos político-pedagógicos e administrativos, além da presença de todos os segmentos do âmbito escolar nos processos de elaboração das políticas das unidades de ensino. 
No estado do Amapá, apresenta-se a Lei no 1.503, de 9 de julho de 2010, dando cumprimento ao artigo 107 da Constituição Estadual. A lei estabelece como elementos da GD: a eleição da equipe gestora, incluindo diretor, diretor adjunto e secretário escolar das unidades escolares; conselho escolar e conselho de classe.

Entre seus principais princípios destacamos a autonomia dos estabelecimentos de ensino na gestão administrativa, financeira e pedagógica; livre organização dos segmentos escolares; garantia de descentralização; transparência dos mecanismos políticos, administrativos, financeiros e pedagógicos, além da eficiência no uso de recursos financeiros e construção coletiva do projeto político-pedagógico.

Ainda na região Norte, o estado de Rondônia promulgou a Lei n ${ }^{\circ} 3.018$, de 17 de abril de 2013. A gestão democrática nessa legislação é assegurada por meio do conselho escolar, da eleição de diretor e vice-diretor, do projeto político pedagógico e do grêmio estudantil.

No Nordeste, o Piauí tem o Decreto n ${ }^{\circ} 12.765$, de 17 de setembro de 2007, que regulamenta o artigo 119, da Lei Complementar $n^{\circ} 71$, de 26 de julho de 2006, que disciplina a gestão democrática nas escolas da rede pública estadual de ensino, compreendendo-a como eixo estruturante da organização escolar a ser conduzida pelo Núcleo Gestor da Escola com o auxílio e a fiscalização do Conselho Escolar.

Esse decreto regulamenta a autonomia da gestão das unidades escolares do estado com a escolha de diretor e seu adjunto, além da constituição dos conselhos escolares, composto por todos os segmentos que compõe a comunidade escolar. Ademais, garante liberdade para a organização estudantil (grêmio estudantil), para o segmento das famílias (APM) e para os trabalhadores da educação, com o seu núcleo de base. Somam-se a esses elementos, a construção coletiva do PPP, do regimento interno e do plano anual de trabalho da escola.

No estado do Rio Grande do Norte, temos a Lei Complementar $n^{\circ} 585$, de 30 de dezembro de 2016. A lei apresenta novidades em relação ao padrão de normatização visto nas demais UF, pois traz a figura da Comissão Estadual Central da GD, que é um coletivo composto por pessoas de diferentes segmentos e setores da educação pública do estado, com vistas a acompanhar a implantação e efetivação da GD nas escolas do estado. Também traz a Assembleia Escolar como uma instância de GD no âmbito escolar. Mais, essa Assembleia se converte na principal instância de discussão e decisão da escola.

Outros destaques da lei são a presença e importância da transparência da gestão na garantia da fiscalização e controle das instituições escolares e descentralização financeira, possibilitando, assim, uma cultura de participação da comunidade escolar. 
No estado de Sergipe, à regulamentação se dá pelo Decreto $n^{\circ} 16.396$, de 20 de março de 1997, que dispõe normas regulamentares sobre a democratização da gestão do ensino público estadual. O estado apresenta também normas complementares específicas que integram o decreto em relação à eleição de diretores e à eleição e implementação do conselho escolar (denominado de comitê escolar). A proposta de gestão aqui apresentada deve contar com a participação dos membros internos e externos da comunidade escolar, de forma representativa nas decisões colegiadas.

Na região Sudeste, apenas o estado do Rio de Janeiro traz uma legislação específica sobre a matéria. Trata-se da Lei $\mathrm{n}^{\circ} 7.365$, de 14 de julho 2016. Contudo, é uma lei com apenas 4 artigos, fazendo menção apenas ao provimento de diretores escolares, que deve estabelecer uma consulta às comunidades para posterior nomeação dos dirigentes, e à organização e funcionamento do conselho escolar.

O estado tem ainda a Lei Estadual $n^{\circ} 1.949$, de 8 de janeiro de 1992, que assegura a livre organização estudantil, e o Decreto $n^{\circ} 44.773$, de 06 de maio de 2014, que cria os conselhos escolares. Assim, a nova lei que o Estado construiu poderia ter agregado elementos que a história do sistema estadual de ensino já havia elaborado.

E no Centro-Oeste brasileiro, os estados de Goiás e Mato Grosso também apresentam legislação específica sobre a GD. No estado de Goiás, temos a Resolução do Conselho Estadual de Educação/CP n ${ }^{\circ} 004 / 2009$, que fixa normas para a gestão democrática nas unidades escolares de educação básica do Sistema Educativo do Estado. Temos aqui, como proposta de gestão democrática do Estado, a eleição do grupo gestor, incluindo diretor, vice-diretor e o secretário geral; o conselho escolar e a criação do grêmio estudantil. Entre alguns princípios da gestão democrática da escola estão à autonomia e à transparência pedagógica e administrativa, bem como o uso adequado de recursos; a livre organização dos segmentos escolares e a efetiva participação dos órgãos colegiados nos processos decisórios da unidade de ensino. Contudo, tais princípios parecem estar sendo relativizados em grande medida com a ênfase na política de transferência de responsabilidades sobre as escolas estaduais da Secretaria da Educação para a Polícia Militar do Estado (SANTOS, 2016), o que é temerário, pois o formato adotado coloca em risco inclusive o modelo de GD indicado pela legislação do próprio Estado.

Já no estado de Mato Grosso, encontramos uma das legislações mais antigas sobre a matéria, ainda em vigência, trata-se da Lei Ordinária $n^{\circ} 7.040$, de $1^{\circ}$ de outubro de 1998, que regulamenta a gestão democrática do ensino público estadual, adotando o sistema seletivo para escolha dos dirigentes dos estabelecimentos de ensino e a criação dos Conselhos Deliberativos da Comunidade 
Escolar nas Unidades de Ensino. Essa lei segue vigendo, mas foi modificada pelas Leis $\mathrm{n}^{\circ} 7.793$, de 04 de dezembro de 2002, e $\mathrm{n}^{0} 7.892$, de 30 de outubro de 2003, em relação ao perfil do candidato para o cargo de gestor escolar.

Ademais, a lei propõe a autonomia pedagógica, administrativa e financeira da escola mediante a organização e funcionamento do conselho deliberativo, enfatiza também a transparência desses mecanismos, bem como a eficiência no uso dos recursos financeiros. A autonomia pedagógica está assegurada na elaboração do plano de desenvolvimento estratégico de escola e da construção do projeto político-pedagógico.

Há muita similitude entre esses dispositivos legais, mesmo que os estados busquem formas distintas de positivar a gestão democrática, uma vez que transparência, autonomia, participação e descentralização são palavras-chave em boa parte das peças legais mencionadas.

Nos demais estados, que ainda não possuem uma legislação única e que concentre os padrões que a UF compreende como tradutores da gestão democrática, temos um quadro diverso. Há, contudo, uma prevalência de legislações que tratam das eleições de diretores e dos conselhos escolares. Estes compõem, com o projeto pedagógico, os tópicos indicados como condições de GD no artigo 14 da LDB como exigências mínimas nacionais para todas as escolas, como vimos. Apesar disso, não encontramos nenhuma legislação estadual que, emblematicamente, trate do PPP como ferramenta de democratização da gestão escolar. O que há são menções ao projeto pedagógico e até mesmo exigências para a sua elaboração, mas incluídas nas peças legais cujo enfoque é outro.

De outro lado, as eleições para diretores estão articuladas a uma luta que remonta aos anos 1980 (SOUZA, 2007a, 2009b), mas não só a legislação nacional as referencia, como, ao contrário, há posicionamento legal contrário a elas (SOUZA, 2007b). As eleições, a despeito disto, continuam sendo lembradas e defendidas pelos movimentos de profissionais da educação e pela literatura (SOUZA, 2007b) como condição da GD escolar.

Os estados que focalizam em ambos os elementos são Amapá e Pará, na região Norte; Pernambuco e Bahia, no Nordeste; Espírito Santo, no Sudeste; e Mato Grosso do Sul, no Centro-Oeste. No entanto, há outros que tratam de um ou outro desses elementos. É o caso de Roraima, no Norte, que tem legislação específica para a regulamentação do Conselho Escolar; Maranhão, no Nordeste; e Paraná, no Sul, que têm legislação apenas sobre o provimento de diretores por meio de eleições.

Entretanto, ainda temos como ferramenta de GD na escola, o Grêmio Estudantil e a Associação de Pais e Mestres, que são abordados por algumas UF, com legislação específica. É o caso do Ceará e da Paraíba, de Minas Gerais e de Santa Catarina. Em Santa Catarina, além do Grêmio, o Estado tem normas 
QUADRO 1 - PANORAMA DA GESTÃO DEMOCRÁTICA DOS ESTADOS E DF

\begin{tabular}{|c|c|c|c|c|c|}
\hline Região & UF & Gestão Democrática ${ }^{1}$ & Diretores $^{2}$ & Conselho Escolar ${ }^{3}$ & Outras Formas $^{4}$ \\
\hline \multirow{7}{*}{$\mathrm{N}$} & $\mathrm{RR}$ & & & & \\
\hline & $\mathrm{AM}$ & & & & \\
\hline & AP & & & & \\
\hline & $\mathrm{AC}$ & & & & \\
\hline & PA & & & & \\
\hline & TO & & & & \\
\hline & RO & & & & \\
\hline \multirow{9}{*}{$\mathrm{NE}$} & MA & & & & \\
\hline & PI & & & & \\
\hline & $\mathrm{CE}$ & & & & \\
\hline & $\mathrm{RN}$ & & & & \\
\hline & PB & & & & \\
\hline & $\mathrm{PE}$ & & & & \\
\hline & $\mathrm{AL}$ & & & & \\
\hline & $\mathrm{SE}$ & & & & \\
\hline & $\mathrm{BA}$ & & & & \\
\hline \multirow{4}{*}{ SE } & ES & & & & \\
\hline & MG & & & & \\
\hline & RJ & & & & \\
\hline & SP & & & & \\
\hline \multirow{3}{*}{$\mathrm{S}$} & $\mathrm{RS}$ & & & & \\
\hline & $\mathrm{SC}$ & & & & \\
\hline & PR & & & & \\
\hline \multirow{4}{*}{$\mathrm{CO}$} & MS & & & & \\
\hline & MT & & & & \\
\hline & $\mathrm{DF}$ & & & & \\
\hline & GO & & & & \\
\hline
\end{tabular}

FONTE: Os autores.

${ }^{1}$ Estados que possuem uma lei específica de gestão democrática no seu sistema de ensino

${ }^{2}$ Estados que possuem decretos, resoluções ou leis específicas sobre a eleição, indicação ou concurso para a função de diretor e vice-diretor no seu sistema de ensino.

${ }^{3}$ Estados que possuem decretos, resoluções ou leis específicas sobre o conselho escolar no seu sistema de ensino.

${ }^{4}$ Estados que possuem outras formas de orientação sobre as criações de conselhos escolares, grêmios estudantis e associação de apoio ou de pais e mestres. 
para lidar com o Conselho Escolar e com as Associações de Pais e Mestres. Em Minas Gerais, a legislação trata do Grêmio, do Conselho Escolar e das eleições para diretores. No Ceará e na Paraíba, encontramos regramento para o Grêmio e para o provimento de diretores escolares.

Finalmente, temos apenas 2 estados, Tocantins e São Paulo, cuja legislação é rudimentar sobre as questões atinentes à gestão democrática. Naquele, tem-se a lei do sistema estadual de ensino, que apenas faz menção à gestão democrática, sem indicar qualquer mecanismo ou procedimento operacional para o princípio legal.

Em São Paulo, há apenas uma legislação sobre algum dos elementos mencionados, que é a Lei $n^{0} 14.689$, de 4 de janeiro de 2012, que dispõe sobre a criação de Associações de Pais e Mestres, uma vez que nem a Constituição do Estado menciona o princípio da GD.

Em outra frente legislativa, quase todos os estados já concluíram a aprovação dos seus respectivos Planos Estaduais de Educação, em associação ao disposto na lei do PNE. Apenas os estados de Minas Gerais e do Rio de Janeiro, este com documento base elaborado e aquele com projeto de lei em tramitação, ainda não possuem planos aprovados. As demais 25 UF aprovaram em seus planos o princípio da gestão democrática, quase como uma cópia do disposto na Lei 13.005/2014; bem como, em 21 desses estados também a meta dedicada à GD é muito similar à meta 19 do Plano Nacional. No entanto, encontramos em três estados (RS, SC e GO) e no DF algumas inovações quanto ao tema. Em nenhum desses quatro planos há menção aos aspectos associados ao mérito como critério de provimento de diretores escolares ou para outra função articulada à GD. Nos casos do RS e do DF, isto era, de alguma forma, esperado, pois são unidades com uma longa tradição na legislação e na luta pela efetivação da gestão democrática.

Todavia, em Santa Catarina vemos um avanço significativo no texto do plano, o que pode trazer frutos promissores para a legislação sobre a GD no estado, ensejando melhores condições para a sua efetivação. Em Goiás, também é auspicioso o roteiro apontado pelo Plano Estadual de Educação, mas, de outro lado, como indicado, o cenário da política educacional neste estado pode comprometer os avanços conquistados com o plano.

Era razoável se esperar que os estados não inovassem muito na elaboração de seus planos educacionais, tendo em vista especialmente a metodologia e o modelo adotados pelo PNE (SOUZA, 2017); contudo, havia aqui um espaço para o desenvolvimento mais autônomo dos sistemas educacionais, que poderiam incorporar os avanços que a própria legislação estadual já havia conquistado. Contudo, isto não se verificou. Cumpre registrar, todavia, que os PEE incorporaram também, em sua maioria, as indicações feitas pelo PNE da necessidade 
de organismos e espaços coletivos para a discussão e tomada de decisões no âmbito da gestão do sistema de ensino. Resta saber se essas indicações serão confirmadas, posteriormente, na prática por meio da atualização da legislação e, principalmente, pela efetivação/criação desses espaços.

\section{Conclusões}

O que apresentamos neste texto evidenciou as formas como as unidades da federação têm se organizado em relação ao princípio constitucional da gestão democrática. Dadas as exigências feitas pela CF 1988, LDB 1996 e PNE 2014, os entes federados têm a responsabilidade de normatizar em sua área o alcance e os procedimentos que garantam a implementação da GD. Vimos que apenas 11 dos 26 estados, além do DF, já possuem normas específicas sobre a matéria, ainda que quase todos os estados apresentem normativas sobre algum dos aspectos concernentes à GD.

No que tange ao alcance, a priorização de virtualmente todos os estados é de focalizar sobre a gestão democrática no âmbito escolar, sem tratar sobre as relações políticas e organizacionais na esfera do sistema educativo como um todo. Isso significa que nas escolas há esforços em se garantir que as relações entre as pessoas sejam pautadas pela democracia, nos processos de discussão, tomada de decisões, acompanhamento de ações, avaliação dos resultados. No entanto, como a escola é parte do sistema de ensino e a gestão deste não é alcançada pelo princípio e procedimentos da GD, ainda que importante, todo aquele esforço de horizontalização das relações nas escolas pode não atingir objetivos mais amplos, como contribuir para a democratização das relações sociais, por exemplo, uma vez que o exercício democrático se encerra nos limites escolares, não chegando às discussões e às decisões da política educacional.

O PNE, assim como todos os PEE já elaborados, todavia, indicam elementos de democratização do sistema educativo por meio da criação e garantia de funcionamento dos Fóruns (Nacional e Estaduais/Distrital), das Conferências de Educação e da melhoria das condições democráticas dos conselhos (de Educação, de Acompanhamento e Controle Social-FUNDEB etc.). Tendo em vista o recente golpe contra o Fórum Nacional de Educação (FNE), é razoável temer que, em um país com pouca solidez nas instituições e que ainda não experimentou a democracia de maneira ampla, tais indicações normativas não sirvam de garantia de implementação da gestão democrática da educação pública. 
Assim, parece-nos que, na análise do material deste estudo, temos um quadro de insuficiência da legislação estadual sobre a gestão democrática, que não se mostra capaz, mesmo muitos anos após a aprovação da CF e da LDB, de traduzir o princípio democrático em regramentos para os seus sistemas.

Para além do levantamento atualizado neste estudo, é também muito importante acompanharmos as formas de elaboração e o conteúdo das legislações sobre a GD nos estados e municípios, pois uma lei que trate da democracia tem que se pretender democrática, o que implica no envolvimento dos distintos segmentos e setores da sociedade na sua formulação. A disposição ao diálogo entre esses sujeitos é determinante na qualidade da peça legal e potencialmente contribuirá para a ampliação das chances do seu cumprimento.

\section{REFERÊNCIAS}

ARRETCHE, M. Federalismo e políticas sociais no Brasil: problemas de coordenação e autonomia. São Paulo Perspectiva, São Paulo, v. 18, n. 2, p. 17-26, abr./jun. 2004. http:// dx.doi.org/10.1590/S0102-88392004000200003.

BOBBIO, N. O futuro da democracia. Tradução: Marco Aurélio Nogueira. São Paulo: Paz e Terra, 2000.

BRASIL. Constituição Federal de 1988. Disponível em: <http://www.planalto.gov.br/ ccivil_03/Constituicao/Constituicao.htm>. Acesso em: nov. 2017.

BRASIL. Lei de Diretrizes e Bases da Educação Nacional, Lei nº 9.394/1996. Disponível em: <http://www.planalto.gov.br/ccivil_03/leis/L9394.htm>. Acesso em: nov. 2017.

BRASIL. Lei do Plano Nacional de Educação, Lei no 13.005/2014. Disponível em: $<$ http://www.planalto.gov.br/ccivil_03/_ato2011-2014/2014/lei/113005.htm>. Acesso em: nov. 2017.

BRASIL. Conselho Nacional de Educação. Termo de Referência n $^{\circ}$ 03/2014. PROJETO CNE/UNESCO - 914BRZ1144.3. Documento técnico contendo estudo analítico sobre o panorama nacional de efetivação da gestão democrática na Educação Básica no Brasil. Brasília: 2014. Disponível em: $<$ http://portal.mec.gov.br/index.php?option=com docman\&view=download\&alias=26111-produto 1 -panorama-nacional-efetivacao-gestao-democratica-edu-basica-pdf\&Itemid=30192 > . Acesso em: nov. 2017.

CAMARGO, R. B. Gestão democrática e nova qualidade de ensino: o conselho de escola e o projeto de interdisciplinaridade nas escolas municipais da cidade de São Paulo (1989-1992). 1997. Tese (Doutorado em Educação) - Universidade de São Paulo, São Paulo, 1997. 
CASTORIADIS, C. A instituição imaginária da sociedade. Tradução: Guy Reynaud. Rio de Janeiro: Paz e Terra, 1995.

DRUMMOND DE ANDRADE, C. Nosso Tempo. In: DRUMMOND DE ANDRADE, C. A rosa do povo. São Paulo: Cia. das Letras, 2012 [1945].

LIMA, L. A escola como organização educativa. São Paulo: Cortez. 2001.

PIRES, P. A. G. Gestão democrática: impasses e desafios para a elaboração da lei estadual 1513 de 11 de novembro de 2003 do Estado do Acre. 2016. Tese (Doutorado em Educação) - Setor de Educação, Universidade Federal do Paraná, Curitiba, 2016.

RIOS, T. A. A autonomia como projeto: horizonte ético-político. In: BORGES, A. et al. (Org.) A autonomia e a qualidade do ensino na escola pública. São Paulo: FDE, 1995. Série Ideias, 16.

SOUZA, Â. R. As relações entre os resultados da avaliação e os modelos de gestão escolar. Intermeio, v. 13, n. 25, p. 64-81, 2007a.

SOUZA, Â. R. Perfil da Gestão da Escola no Brasil. 2007. Tese (Doutorado em Educação) - Pontifícia Universidade Católica, São Paulo. 2007b.

SOUZA, Â. R. Explorando e construindo um conceito de gestão democrática. Educação em Revista, Belo Horizonte, v. 25, n. 3, p. 123-140, dez. 2009a.

SOUZA, Â. R. Perfil da gestão da escola pública no Brasil: um estudo sobre os diretores escolares e sobre aspectos da gestão democrática. Revista Iberoamericana de Educación, v. 49 , n. 2, p. 1-17, 2009b.

SOUZA, Â. R. A pesquisa em políticas educacionais no Brasil: de que estamos tratando? Práxis Educativa, UEPG, Ponta Grossa, v. 9, p. 355-367, 2014.

SOUZA, Â. R. Políticas de democratização da gestão educacional no Brasil: experiência e expectativa com o novo Plano Nacional de Educação. Revista Pedagógica, Unochapecó, v. 18, p. 111-128, 2017.

SOUZA, Â. R.; BRUEL, A. L. Sindicalismo Docente e a Gestão Democrática da Educação no Brasil. Interacções, v. 12, p. 192-210, 2016.

SANTOS, R. J. da C. A militarização da escola pública em Goiás. Dissertação (Mestrado em Educação) - Pontifícia Universidade Católica, Goiânia. 2016.

\section{Legislação sobre GD nos estados da federação}

ACRE. Assembleia Legislativa do Estado do Acre. Lei $n^{\circ} 3.141$, de 22 de julho de 2016. Dispõe sobre a gestão democrática de ensino público do Estado do Acre e dá outras providências. Disponível em: <http://www.aleac.ac.gov.br>. Acesso em: nov. 2017. 
ALAGOAS. Lei $n^{\circ}$ 6.152, de 11 de maio de 2000. Disponível em: <http://www.educacao.al.gov.br/component/jdownloads/send/70-2000/180-file-lei-n-6-152-de-11-0500? option $=\mathrm{com} \_$jdownloads $>$. Acesso em: nov. 2017.

ALAGOAS. Lei $n^{\circ} 6.628$, de 21 de outubro de 2005. Institui novas regras para a gestão na rede pública estadual de ensino, como espaço de participação e construção coletiva, através de novas diretrizes quanto às eleições diretas para diretor e diretor-adjunto das escolas de educação básica, dando outras providências. Portal da Legislação. Disponível em: <http://www.educacao.al.gov.br/legislacao>. Acesso em: nov. 2017.

ALAGOAS. Lei no 6.661, de 28 de dezembro de 2005. Dispõe sobre a criação dos conselhos escolares sob a forma de sociedade civil, nas unidades de educação básica da rede estadual de ensino. Portal da Legislação. Alagoas. Disponível em: <http://www. educacao.al.gov.br/legislacao>. Acesso em: nov. 2017.

AMAPÁ. Lei $n^{\circ} 1.503$, de 9 de julho de 2010. Regulamenta a gestão democrática escolar nas unidades escolares da rede estadual de ensino. Portal da Legislação. Amapá. Disponível em: <http://www.al.ap.gov.br/ver_texto_lei.php?iddocumento=25541>. Acesso em: out. 2017.

AMAZONAS. CEE/AM. Resolução $n^{\circ}$ 122/2010. Regimento Geral das Escolas Estaduais do Amazonas.

BAHIA. Decreto $n^{\circ} 13.202$ de 19 de agosto de 2011. Regulamenta o artigo 18 da Lei $n^{\circ}$ 8.261 , de 29 de maio de 2002, dispondo sobre os critérios e procedimentos do processo seletivo interno a ser realizado pela unidade escolar, requisito para o preenchimento dos cargos de Diretor e Vice-diretor das Unidades Escolares do Estado da Bahia, e dá outras providências. Portal da Legislação. Bahia. Disponível em: <http://www.sec.ba.org.br./>. Acesso em: out. 2017.

BAHIA. Lei $n^{\circ} 11.043$, de 09 de maio de 2008. Criação, finalidade e competência do colegiado escolar. Portal da Legislação. Bahia. Disponível em: <http://www.sec.ba.org. br./>. Acesso em: out. 2017.

CEARÁ. Lei $n^{\circ} 13.513$, de 19 de julho de 2004. Dispõe sobre o processo de escolha e indicação para o cargo de provimento em comissão de Diretor junto às Escolas da Rede Pública Estadual de Ensino, dando também outras providências. Portal da Legislação. Ceará. Disponível em: <http://www.seduc.ce.gov.br/>. Acesso em: nov. 2017.

CEARÁ. Lei $n^{\circ} 13.433$, de 6 de janeiro de 2004. Dispõe sobre a livre organização de Grêmios Estudantis. Portal da Legislação. Ceará. Disponível em: < http://www.seduc. ce.gov.br/>. Acesso em: nov. 2017.

DISTRITO FEDERAL. Lei $n^{\circ} 4.751$, de fevereiro de 2012. Dispõe sobre o sistema de ensino e a gestão democrática do sistema de ensino público. Portal da Legislação. Distrito Federal. Disponível em: <http://www.se.df. gov.br/>. Acesso em: set. 2017.

ESPÍRITO SANTO. Regimento Comum das Escolas da Rede Estadual, 2010. 
ESPÍRITO SANTO. Portaria $n^{\circ}$ 111-R. Dispõe sobre a organização dos conselhos de escolas. Disponível em: $<\mathrm{http}: / /$ sedu.es.gov.br/Media/sedu/pdf\%20e\%20Arquivos/111-R->. Acesso em: nov. 2017.

GOIÁS. Resolução do CEE/CP $n^{\circ}$ 004/2009. Fixa normas para a gestão democrática nas unidades escolares de educação básica do Sistema Educativo do Estado. Portal da Legislação. Goiás. Disponível em: <http://www.educacao.go gov.br/>. Acesso em: nov. 2017.

MARANHÃO. Decreto $n^{\circ} 30.619$, de 02 de janeiro de 2015. Dispõe sobre o processo seletivo democrático para a função de gestão escolar das unidades de ensino da rede pública. Portal da Legislação. Maranhão. Disponível em: <http://www.educacao.ma.gov. br/>. Acesso em: nov. 2017.

MATO GROSSO. Lei Ordinária $n^{\circ} 7.040$, de $1^{\circ}$ de outubro de 1998. Regulamenta a gestão democrática do ensino público estadual, adotando o sistema seletivo para escolha dos dirigentes dos estabelecimentos de ensino e a criação dos Conselhos Deliberativos da Comunidade Escolar nas Unidades de Ensino. Portal da Legislação. Mato Grosso. Disponível em: <http://www.seduc.mt. gov.br/>. Acesso em: set. 2017.

MATO GROSSO DO SUL. Lei ${ }^{\circ} 3.244$, de 06 de junho de 2006. Dispõe sobre o processo eletivo de dirigentes escolares e adjuntos e dos conselhos escolares da rede estadual de ensino. Portal da Legislação. Mato Grosso do Sul. Disponível em: <http://www.sed. ms.gov.br/>. Acesso em: out. 2017.

MINAS GERAIS. Lei $n^{\circ} 12.084$, de 12 de janeiro de 1996. Assegura a livre organização estudantil e dá outras providências no estado de Minas Gerais. Disponível em: $<$ https:// www.almg.gov.br/consulte/legislacao/completa/completa.html?tipo=Lei\&num=12084 $\&$ comp $=\& a n o=1996>$. Acesso em: set. 2017.

MINAS GERAIS. Decreto $n^{\circ}$ 43.602, de 2003. Portal da Legislação. Minas Gerais. Disponível em: <http://www.almg.gov.br/consulte/arquivo...legislativo/>. Acesso em: set. 2017.

MINAS GERAIS. Resolução $n^{\circ} 1.812$, de 22 de março de 2011. Secretaria Estadual Educação, que estabelece critérios e condições para a seleção de candidatos ao cargo de Diretor e à função de vice-diretor das unidades estaduais de ensino, escolhidos pela comunidade escolar. Portal da Legislação. Minas Gerais. Disponível em: $<$ http://www. educacao.mg. gov.br/>. Acesso em: set. 2017.

PARÁ. Instrução Normativa $n^{o} 03 / G S$, de 16/02/2009, de acordo com a Portaria $n^{o}$ 04/2009-GS. Portal da Legislação. Pará. Disponível em: <http://www.seed.pa.gov.br/>. Acesso em: 05 nov. 2012.

PARÁ. Resolução $n^{\circ}$ 436/2004 CEE/PA. Regimento Geral das Escolas Estaduais do Pará, em seu título III e VII, dispõe sobre a criação dos órgãos colegiados. Disponível em: $<$ https://ntetucurui.files.wordpress.com/2009/11/regimento_escolas_parc3a1.pdf $>$. Acesso em: set. 2017. 
PARAÍBA. Lei $n^{\circ} 7.983$, de 10 de abril de 2006. Dispõe sobre o processo de eleição de diretor e vice-diretor das unidades de ensino da rede estadual. Portal da Legislação. Paraíba. Disponível em: <http://www.paraíba.pb.gov.br/educacao>. Acesso em: nov. 2017.

PARAÍBA. Lei $n^{\circ}$ 9.372, de 3 de junho de 2011. Institui a campanha de incentivo aos Grêmios Estudantis nas unidades escolares da rede estadual de ensino e dá outras providências. Portal da Legislação. Paraíba. Disponível em: <http://www.paraíba.pb.gov. br/educacao $>$. Acesso em: nov. 2017.

PARANÁ. Portaria $n^{\circ}$ 011-R, de 12 de fevereiro de 2010. Dispõe sobre a organização dos conselhos de escola das unidades escolares como unidades executoras de recursos financeiros e dá outras providências. Portal da Legislação. Paraná. Disponível em: <http:// www.seed.pr. gov.br/>. Acesso em: out. 2017.

PARANÁ. Lei ${ }^{\circ} 18.590$, de 13 de outubro de 2015. Dispõe sobre a definição de critérios de escolha mediante a consulta à Comunidade Escolar para designação de Diretores. Disponível em: $<$ http://www.legislacao.pr.gov.br/legislacao/pesquisarAto.do?action=ex ibir\&codAto=147837\&codItemAto=904159>. Acesso em: out. 2017.

PARANÁ. Deliberação 02/2015 - CEE/PR. Dispõe sobre as normas para a Educação em DH. Disponível em: <http://www.gestaoescolar.diaadia.pr.gov.br/arquivos/File/ sem_pedagogica/fev_2016/anexo2_1dia_sp2016.pdf>. Acesso em: out. 2017.

PERNAMBUCO. Decreto $n^{\circ} 38.103$, de 25 de abril de 2012. Regulamenta os critérios e procedimentos para realização de processo de seleção para função de representação de diretor escolar e diretor-adjunto das escolas estaduais, dando também outras providências. Portal da Legislação. Pernambuco. Disponível em: $<$ http://www.educacao.pe.gov. br/legislacao>. Acesso em: nov. 2017.

PERNAMBUCO. Lei $n^{\circ} 11.014$ de 28 de dezembro de 1993. Dispõe sobre a criação dos Conselhos Escolares. Disponível em: $<$ http://legis.alepe.pe.gov.br/texto.aspx?id=6262 \&tipo=TEXTOORIGINAL $>$. Acesso em: nov. 2017,

PIAUÍ. Decreto $n^{\circ} 12.765$, de 17 de setembro de 2007. Regulamenta o Art. 119, da Lei Complementar $\mathrm{n}^{\circ} 71$, de 26 de julho de 2006, disciplinando a gestão democrática nas escolas da rede pública estadual de ensino no Piauí e dá outras providências. Portal da Legislação. Piauí. Disponível em: <http://www.seduc.pi.gov.br/>. Acesso em: out. 2017.

RIO DE JANEIRO. Lei Estadual $n^{\circ} 1.949$, de 8 de janeiro de 1992. Assegura a livre organização estudantil e dá outras providências no Estado do Rio de Janeiro. Portal da Legislação. Rio de Janeiro. Disponível em: <http://www.rj.gov.br/web/seeduc/>. Acesso em: nov. 2017.

RIO DE JANEIRO. Decreto $n^{\circ} 44.773$, de 06 de maio de 2014. Cria os conselhos escolares nos estabelecimentos de ensino de educação básica da rede pública estadual. Portal da Legislação. Rio de Janeiro. Disponível em: <http://www.rj.gov.br/web/seeduc/>. Acesso em: nov. 2017. 
RIO DE JANEIRO. Lei $n^{\circ} 7.365$, de 14 de julho 2016. Regulamenta o princípio da gestão democrática. Disponível em: $<$ http://alerjln1.alerj.rj.gov.br/contlei.nsf/e9589b9aabd9cac8032564fe0065abb4/b43af28cb7dbdb2983257ff10065f101? OpenDocument $>$. Acesso em: nov. 2017.

RIO GRANDE DO NORTE. Lei Complementar $n^{\circ}$ 585, de 30 de dezembro de 2016. Dispõe sobre a Gestão Democrática e Participativa da Rede Pública Estadual de Ensino do Rio Grande do Norte. Disponível em: < http://www.diariooficial.rn.gov.br/dei/dorn3/ docview.aspx?id_jor $=00000001 \&$ data $=20161231 \&$ id_doc $=559551>$. Acesso em: nov. 2017.

RIO GRANDE DO SUL. Lei $n^{\circ} 10.576$, de 14 de novembro de 1995. Dispõe sobre a gestão democrática do ensino público e dá outras providências. Portal da Legislação. Porto Alegre. Disponível em: <http://www.educacao.rs.gov.br/>. Acesso em: set. 2017.

RIO GRANDE DO SUL. Lei $n^{\circ} 13.990$, de 15/05/2012. Altera dispositivos da lei 10576/1995. Disponível em: <http://cpersnucleo39.blogspot.com.br/2012/05/anexo-segue-lei-n-13.html>. Acesso em: set. 2017.

RONDÔNIA. Lei $n^{\circ}$ 3.018, de 17 de abril de 2013. Dispõe sobre a gestão democrática na rede pública estadual de ensino de Rondônia e dá outras providências. Portal da Legislação. Rondônia. Disponível em: < http://ditel.casacivil.ro.gov.br/cotel/Livros/Files/ L3018.pdf>. Acesso em: out. 2017.

RONDÔNIA. Lei n. 3.162, de 27 de agosto de 2013. Altera dispositivos da lei 3018/2013. Portal da Legislação. Rondônia. Disponível em: <http://ditel.casacivil.ro.gov.br/cotel/ Livros/Files/L3162.pdf>. Acesso em: out. 2017.

RORAIMA. Lei $n^{\circ} 810$, de 6 de julho de 2011. Dispõe sobre a reorganização dos conselhos escolares do sistema estadual de ensino, sendo órgão de deliberação coletiva, de caráter consultivo, podendo também acompanhar, fiscalizar e avaliar a gestão administrativa, pedagógica e financeira da unidade escolar. Portal da Legislação. Roraima. Disponível em: <http:/www.tjrr.jus.br/leisOrdinarias/2011/LeiEstadual/810-2011>. Acesso em: set. 2017.

SANTA CATARINA. Decreto $n^{\circ} 31.113$, de 18 de dezembro de 1986. Dispõe sobre a existência e criação das associações de pais e professores. Portal da Legislação. Santa Catarina. Disponível em: <http://www.sed.sc. gov.br/>. Acesso em: nov. 2017.

SANTA CATARINA. Decreto Estadual n ${ }^{\circ} 3.429$, de 08/12/98. Regulamenta a implementação do conselho como entidade colegiada de caráter consultivo, normativo, deliberativo e avaliativo para atuar em assuntos referentes à gestão pedagógica, administrativa e financeira da unidade escolar no Estado catarinense. Portal da Legislação. Santa Catarina. Disponível em: <http://www.sed.sc. gov.br/>. Acesso em: nov. 2017.

SANTA CATARINA. Lei Complementar $n^{\circ}$ 170/98. Dispõe sobre o Sistema Estadual de Educação do Estado. Portal da Legislação. Santa Catarina. Disponível em: <http:// www.sed.sc. gov. br/>. Acesso em: nov. 2017. 
SANTA CATARINA. Lei Estadual $n^{\circ} 12.731 / 03$. Dispõe sobre a organização de entidades representativas dos estudantes. Portal da Legislação. Santa Catarina. Disponível em: <http://www.sed.sc. gov.br/>. Acesso em: nov. 2017.

SÃO PAULO. Resolução $n^{\circ} 21$, de 10 de fevereiro de 2012. Dispõe sobre a implementação do Programa "Aprimoramento da Gestão Participativa". Portal da Legislação. São Paulo. Disponível em: <http://www.educacao.sp.org.br./>. Acesso em: nov. 2017.

SERGIPE. Decreto $n^{\circ} 16.396$, de 20 de março de 1997. Dispõe normas regulamentares sobre a democratização da gestão do ensino público estadual, de acordo com os artigos 171 e 172 da Lei Complementar n 16/94, que trata do Estatuto do Magistério Público do Estado de Sergipe, e dá providências. Portal da Legislação. Sergipe. Disponível em: $<$ http://www.seed.se. gov.br/>. Acesso em: set. 2017.

TOCANTINS. Lei $n^{\circ} 2139$, de 3 de setembro de 2009. Dispõe sobre o sistema estadual de ensino e dá outras providências. Portal da Legislação. Tocantins. Disponível em: $<$ http://www.al.to.gov.br/>. Acesso em: nov. 2017.

Texto recebido em 18 de janeiro de 2018. Texto aprovado em 30 de janeiro de 2018. 
